\title{
Short Term Propofol Anaesthesia Is Not Associated with an Increase in Blood Lactate: A Comparative Study with Sevoflurane
}

\author{
Constance Sat Lin Liew, ${ }^{1,}$, T. Kumaravadivel Dharmalingam², Nik Abdullah Nik Mohamad ${ }^{2}$ \\ ${ }^{1}$ Department of Anaesthesiology, Universiti Malaysia Sabah, Sabah, Malaysia \\ ${ }^{2}$ Department of Anaesthesiology, Hospital Universiti Sains Malaysia, Kelantan, Malaysia
}

Email address:

constance.liew@yahoo.com (C. S. L. Liew),dtkumar123@yahoo.com (T. K. Dharmalingam), nikabdullah@usm.my (N. A. N. Mohamad) ${ }^{*}$ Corresponding author

\section{To cite this article:}

Constance Sat Lin Liew, T. Kumaravadivel Dharmalingam, Nik Abdullah Nik Mohamad. Short Term Propofol Anaesthesia Is Not Associated with an Increase in Blood Lactate: A Comparative Study with Sevoflurane. Journal of Anesthesiology. Vol. 4, No. 2, 2016 , pp. 5-10. doi: $10.11648 /$ j.ja.20160402.11

Received: April 28, 2016; Accepted: May 10, 2016; Published: June 13, 2016

\begin{abstract}
This research was conducted considering the fact that today, there are still very few studies comparing Sevoflurane or Target Controlled Infusion using Propofol in term of serum lactate accumulation during general anaesthesia. There were 92 patients aged 18-65 years old, classified under ASA I, were involved in this prospective study. They were divided into 2 groups and this study was done in a double-blind manner. Patients received either Sevoflurane inhalational or Propofol infusion using Marsh model (target plasma concentration of $5 \mathrm{mcg} / \mathrm{ml}$ ) during operation. All the patients received anaesthesia in a standard practice and blood samples were taken at every hour until completion of operation. The blood samples were tested for acid-base values and lactate level. There are significant differences in the mean values of serum lactate levels at $1^{\text {st }}, 2^{\text {nd }}, 3^{\text {rd }}$ and $4^{\text {th }}$ hour of surgery within propofol and sevoflurane group with $p$ value of $<0.05$. Nevertheless, when comparing differences in the mean values of serum lactate levels between propofol and sevoflurane group showed no significant difference of serum lactate change with $\mathrm{p}=0.186$. In conclusion, our study shows that short term anaesthesia with sevoflurane is associated with an increase blood lactate levels more than lactate levels observed during high dose propofol anaesthesia.
\end{abstract}

Keywords: Propofol, Sevoflurane, Lactate, Acidosis, Anaesthesia

\section{Introduction}

Propofol is an intravenous short-acting sedative hypnotic agent that has been in use for over three decades. It has a rapid onset of action within seconds and a very short half-life about 3 to 10 minutes. It was initially used as an inducing agent for general anaesthesia. The short context-sensitive half-time of propofol, even with prolonged periods of infusion, combined with the short effect-site equilibration time, make this an easily titratable drug for production of intravenous sedation [1]. The prompt recovery without residual sedation, vomiting and nausea make this drug well suited for short duration surgical procedures. The non-renal, non-hepatic dependent rapid metabolic clearance makes it a superior agent over benzodiazepines or opioids.

The typical conscious sedation dose for propofol is 25 to $100 \mu \mathrm{g} / \mathrm{kg} / \mathrm{min}$ intravenous produces minimal analgesic and amnestic effects. The dose for maintenance of anaesthesia is $100-300 \mu \mathrm{g} / \mathrm{kg} / \mathrm{minute}$ intravenous, often in combination with a short acting opioid [2]. Propofol is both a cardiovascular and a respiratory depressant; however, the risk of these effects can be lessened by appropriate dosage adjustment. Anaphylaxis with propofol is a rare event [1]. Propofol can be administered as part of an anaesthesia technique called Total Intravenous Anaesthesia (TIVA) using specialized microprocessor computer controlled infusion pumps in a process called Target Controlled Infusion (TCI).

In an un-premedicated patient, plasma concentration of propofol required to produce loss of consciousness is about 5 
to $6 \mu \mathrm{g} / \mathrm{ml}$. In premedicated patients it is $4-5 \mathrm{mcg} / \mathrm{ml}$. patients waking from anaesthesia have a blood concentration of around $1-2 \mu \mathrm{g} / \mathrm{ml}$. In the majority of these patients, an increase in lactate and development of metabolic acidosis was apparent early, within 2-5 hours after initiation of anaesthetic doses of propofol infusion. A significant increase in arterial lactate level over time was observed in propofol infusion group by $0.48 \pm 0.7 \mathrm{mmol} / \mathrm{L}$ [3].

Lactic acidosis is a broad-anion gap metabolic acidosis caused by lactic acid overproduction or underutilization. Overproduction of lactic acid, also termed type A lactic acidosis, occurs when the body must regenerate ATP without oxygen in tissue hypoxia. Circulatory, pulmonary, or haemoglobin transfer disorders are commonly responsible [4]. There is possible that compromised lactate metabolism occurs without hypoxia, which is frequently termed type B (slow) lactic acidosis; the causes include high glycolysis rates attributable to low cytosolic ATP levels in vigorous exercise, uncoupled oxidative phosphorylation, decreased breakdown of lactate in thiamine deficiency, high levels of ATP production from fat or low rates of ATP synthesis, and low levels of conversion of lactate to glucose; or defects in gluconeogenesis resulting from side effects of drugs or inborn errors of metabolism [4].

In an animal study on 23 live rodent brains in 2011 at health science center, stony brook university USA revealed that volatile (isoflurane) and intravenous (propofol) anaesthetics at equipotent doses produce distinct metabolomic profiles in the hippocampus and parietal cortex of the live rodent. For both brain regions, prolonged isoflurane anaesthesia was characterized by higher levels of lactate and glutamate compared with long-lasting propofol. In contrast, propofol anaesthesia was characterized by very low concentrations of lactate. Quantitative analysis revealed that the lactate was fivefold higher with isoflurane compared with propofol anaesthesia and independent of lactate in blood [5].

Sevoflurane $\left(\mathrm{CFH}_{2}-\mathrm{O}-\mathrm{CH}\left(\mathrm{CF}_{3}\right)_{2}\right)$ was first tested in the 1970 but was set aside because of expensive synthesis and metabolism to inorganic fluoride. Interest in sevoflurane has been rekindled because its low tissue solubility and pleasant odour allow good patient acceptance and rapid inhaled induction [6].

Sevoflurane depresses cardiovascular function in dose related manner as with all other inhalational agents. However, these negative inotropic effect is mild if compare with other inhalational agents such as halothane or isoflurane. Sevoflurane decreases the blood pressure by decreasing the systemic vascular resistance but doesn't cause reflex tachycardia. It is also less arrythmogenic since it is ether and not an alkane. Sevoflurane does not produce coronary artery vasodilatation that could lead to coronary artery steal syndrome. Sevoflurane is metabolized to inorganic fluoride but there is no concern for nephrotoxicity as the concentration of fluoride in the kidney is very minimal. However, sevoflurane should be used with concern in patients with renal insufficiency. Sevoflurane is principally excreted via lungs. The depth of anaesthesia changes rapidly following changes in the inspired concentration of sevoflurane. Emergence and recovery are particularly rapid. For these reasons, sevoflurane is acceptable for inhalation induction of anaesthesia [7].

The primary goal of this study is to investigate and compare the lactate accumulation during propofol TCI versus volatile sevoflurane in short duration surgical procedures. This research was conducted considering the fact that today, there are still very few studies comparing Sevoflurane or Target Controlled Infusion using Propofol in term of serum lactate accumulation during general anaesthesia.

\section{Materials and Method}

Ethical approval was obtained from Hospital Universiti sains Malaysia (FWA00007718, IRB00004494) and complied with Declaration of Helsinki. Patients $(n=92)$ of ASA physical status I age between 18-65 years scheduled for various orthopedic elective surgeries lasting for more than 4 hours duration and received general anaesthesia were included in the study. Patients with clinically significant cardiovascular, pulmonary, renal or hepatic disease or hypersensitivity to sevoflurane were excluded.

This was a randomized, double blind prospective clinical trial, where patients were randomly assigned to one of the two groups. In Group A anaesthesia was induced with propofol $(2 \mathrm{mg} / \mathrm{kg})$ and maintained with propofol infusion (25 to $100 \mu \mathrm{g} / \mathrm{kg} / \mathrm{min}$ ) to achieve a target plasma concentration of $5 \mu \mathrm{g} / \mathrm{ml}$ using a B Braun ${ }^{\circledR}$ Space Perfusor (B. Braun Medical Supplies, Melsungen, Germany). In Group B, anaesthesia was induced with propofol $(2 \mathrm{mg} / \mathrm{kg})$ and was maintained with Sevoflurane (2-3\%).

Clinical examination was done to ensure that patients are suitable for operation. Routine investigations like hemoglobin, renal function tests, serum electrolytes, random blood sugar, and chest X-ray were conducted. On the table, monitors were attached and vital parameters like pulse, blood pressure, $\mathrm{SpO}_{2}, \mathrm{ECG}$ and temperature were monitored. To ensure adequate depth of anaesthesia, Bispectral Index Score (BIS) was monitored and the patients were evaluated for level of anaesthesia (target BIS score 40-60) during the operative period.

During Induction, all patients were induced with intravenous fentanyl $1-2 \mu \mathrm{g} / \mathrm{kg}$, followed by initial single bolus dose of propofol $2 \mathrm{mg} / \mathrm{kg}$. Intravenous rocuronium (1 $\mathrm{mg} / \mathrm{kg}$ ) was administered $1 \mathrm{~min}$ following propofol injection after loss of consciousness. Maintenance doses of rocuronium $150 \mu \mathrm{g} / \mathrm{kg}$ were administered at every 15 to 20 min interval.

A cannula (size 20 or 22 gauge) was inserted into the radial artery. Allen test was performed prior to radial artery cannulation to confirm that the patency of the artery is normal. A baseline arterial blood sample $(2 \mathrm{ml})$ was drawn out after induction of anaesthesia. The blood was then for arterial blood gases analysis, acid-base level and lactate level using Radiometer ABG machine (ISE Method, Radiometer ABL5 Analyzer, (STM: MPK/DL 02) ABL 800 Basic 
(STM:MPK/DL 34). Sampling was conducted every hour until completion of operation within $30 \mathrm{~min}$ of the specified study point.

At the end of the operation, the patients were reversed from anaesthesia by a standard practice using intravenous atropine $0.02 \mathrm{mg} / \mathrm{kg}$ and intravenous neostigmine 0.04 $\mathrm{mg} / \mathrm{kg}$. Patients were sent to the recovery room for postanaesthesia monitoring for 30 minutes and then were sent to their respective wards.

\section{Results}

Patients $(n=92)$ were divided in 2 groups. The patients in our study belongs to age group 18-65 years. There were no significant difference in the mean age or weight and sex distribution among patients between two groups. Table 1 shows that the propofol group (Group A) has higher mean age group when compared to sevoflurane group (Group B), with $32.17 \pm 12.83$ for Group A versus $30.60 \pm 12.30$ years old in Group B. There were $44.1 \%$ of male patients in Sevoflurane group (Group B) compared to $55.9 \%$ in the propofol group (Group A). The rests are female patients. However, the differences were not significant. (Table 2)

Table 1. Demography of Patients Comparison of Age and Weight between group $A$ and group $B(n=92)$.

\begin{tabular}{lll}
\hline & Group Mean (SD) & \\
\hline Variable & Propofol $(\mathbf{n}=46)$ & Sevoflurane $(\mathbf{n}=46)$ \\
\hline Age (years) & $32.17(12.83)$ & $30.60(12.30)$ \\
Weight $(\mathrm{kg})$ & $65.55(13.24)$ & $66.05(10.05)$ \\
BMI $\left(\mathrm{kg} / \mathrm{m}^{2}\right)$ & $22.87(3.10)$ & $23.46(3.35)$ \\
\hline
\end{tabular}

Table 2. Comparison of Gender between group A and group B ( $n=92)$.

\begin{tabular}{llll}
\hline \multicolumn{5}{c}{ Group n (\%) } & & \\
\hline Gender & Propofol $(\mathbf{n}=\mathbf{4 6})$ & Sevoflurane $(\mathbf{n}=\mathbf{4 6})$ & P value \\
\hline Male & $33(55.9)$ & $26(44.1)$ & 0.601 \\
Female & $13(39.4)$ & $20(60.6)$ & 0.128 \\
\hline
\end{tabular}

*Chi-square Test.

Table 3. Comparison of Electrolytes and Acid-Base Differences between Group $A$ and group B $(n=92)$.

\begin{tabular}{|c|c|c|c|}
\hline \multirow[b]{2}{*}{ Variable } & \multicolumn{2}{|c|}{ Group Mean (SD) } & \multirow[b]{2}{*}{$P$ value } \\
\hline & $\begin{array}{l}\text { Propofol } \\
(n=46)\end{array}$ & $\begin{array}{l}\text { Sevoflurane } \\
(n=46)\end{array}$ & \\
\hline $\mathrm{pH}$ & $7.40(0.05)$ & $7.39(0.05)$ & 0.510 \\
\hline $\mathrm{HCO}_{3}{ }^{-}(\mathrm{mmol} / \mathrm{L})$ & $23.56(2.09)$ & $24.08(3.50)$ & 0.392 \\
\hline Base Excess $(\mathrm{BE})(\mathrm{mmol} / \mathrm{L})$ & $-1.37(2.58)$ & $-0.15(3.88)$ & 0.082 \\
\hline $\mathrm{pCO}_{2}(\mathrm{mmHg})$ & $36.99(4.44)$ & $37.91(6.49)$ & 0.428 \\
\hline Glucose $(\mathrm{mmol} / \mathrm{L})$ & $6.57(5.73)$ & $5.82(0.84)$ & 0.378 \\
\hline Sodium $\left(\mathrm{Na}^{+}\right)(\mathrm{mmol} / \mathrm{L})$ & $136.80(3.11)$ & $136.54(2.79)$ & 0.673 \\
\hline Potassium $\left(\mathrm{K}^{+}\right)(\mathrm{mmol} / \mathrm{L})$ & $3.83(0.39)$ & $3.80(0.37)$ & 0.703 \\
\hline Lactate $(\mathrm{mmol} / \mathrm{L})$ & $0.926(0.19)$ & $1.007(0.33)$ & 0.159 \\
\hline
\end{tabular}

*independent t-test

There were no significant difference in electrolytes and acid-base values between the two groups with $p$ value of $>0.05$.
Table 4. Intraoperative Electrolytes and Acid-Base Values between Group A and Group B.

\begin{tabular}{|c|c|c|c|}
\hline \multirow[b]{2}{*}{ Variable } & \multicolumn{3}{|l|}{ Group Mean (SD) } \\
\hline & Propofol $(n=46)$ & Sevoflurane $(n=46)$ & P value \\
\hline MAP (mmHg) & $88.1(10.00)$ & $84.6(14.46)$ & 0.178 \\
\hline HR & $77.8(11.02)$ & $77.7(12.38)$ & 0.972 \\
\hline $\begin{array}{l}\text { Core temperature } \\
\left({ }^{\circ} \mathrm{C}\right)\end{array}$ & $36.5(0.74)$ & $36.4(0.61)$ & 0.492 \\
\hline \multicolumn{4}{|l|}{$\mathrm{PH}$} \\
\hline Pre-op & $7.40(0.05)$ & $7.40(0.05)$ & 0.510 \\
\hline $1 \mathrm{H}$ & $7.40(0.05)$ & $7.40(0.05)$ & 0.511 \\
\hline $2 \mathrm{H}$ & $7.41(0.04)$ & $7.39(0.06)$ & 0.112 \\
\hline $3 \mathrm{H}$ & $7.38(0.06)$ & $7.40(0.06)$ & 0.126 \\
\hline $4 \mathrm{H}$ & $7.38(0.05)$ & $7.39(0.05)$ & 0.300 \\
\hline \multicolumn{4}{|l|}{$\mathrm{PaCO}_{2}(\mathrm{mmHg})$} \\
\hline Pre-op & $36.99(4.44)$ & $37.92(6.49)$ & 0.428 \\
\hline $1 \mathrm{H}$ & $36.99(4.44)$ & $37.92(6.49)$ & 0.421 \\
\hline $2 \mathrm{H}$ & $37.38(5.17)$ & $38.49(5.45)$ & 0.357 \\
\hline $3 \mathrm{H}$ & $38.85(5.32)$ & $38.70(5.89)$ & 0.345 \\
\hline $4 \mathrm{H}$ & $39.00(6.03)$ & $38.55(6.41)$ & 0.745 \\
\hline \multicolumn{4}{|l|}{$\mathrm{HCO}_{3}^{-}(\mathrm{mmol} / \mathrm{L})$} \\
\hline Pre-op & $23.56(2.09)$ & $24.08(3.50)$ & 0.392 \\
\hline $1 \mathrm{H}$ & $23.56(2.09)$ & $24.08(3.50)$ & 0.391 \\
\hline $2 \mathrm{H}$ & $23.89(2.20)$ & $23.67(3.11)$ & 0.697 \\
\hline $3 \mathrm{H}$ & $22.89(2.30)$ & $23.62(2.91)$ & 0.185 \\
\hline $4 \mathrm{H}$ & $23.24(1.99)$ & $23.49(2.48)$ & 0.605 \\
\hline \multicolumn{4}{|c|}{ Base Excess $(\mathrm{BE})(\mathrm{mmol} / \mathrm{L})$} \\
\hline Pre-op & $-1.37(2.59)$ & $-0.15(3.88)$ & 0.082 \\
\hline $1 \mathrm{H}$ & $-1.37(2.59)$ & $-0.15(3.88)$ & 0.081 \\
\hline $2 \mathrm{H}$ & $-0.97(2.76)$ & $-0.84(3.69)$ & 0.841 \\
\hline $3 \mathrm{H}$ & $-1.95(2.83)$ & $-1.03(3.39)$ & 0.161 \\
\hline $4 \mathrm{H}$ & $-1.60(2.14)$ & $-0.83(3.40)$ & 0.200 \\
\hline \multicolumn{4}{|l|}{ Lactate $(\mathrm{mmol} / \mathrm{L})$} \\
\hline Pre-op & $0.93(0.19)$ & $1.01(0.33)$ & 0.159 \\
\hline $1 \mathrm{H}$ & $0.93(0.19)$ & $1.01(0.33)$ & 0.160 \\
\hline $2 \mathrm{H}$ & $1.06(0.27)$ & $1.12(0.31)$ & 0.314 \\
\hline $3 \mathrm{H}$ & $1.27(0.39)$ & $1.30(0.39)$ & 0.670 \\
\hline $4 \mathrm{H}$ & $1.21(0.35)$ & $1.35(0.46)$ & 0.118 \\
\hline
\end{tabular}

The changes during operations values of electrolytes and acid-base were tested using independent t-test. Table- 4 showed there were no significant difference in $\mathrm{pH}, \mathrm{pCO}_{2}, \mathrm{HCO}_{3}{ }^{-}$, base excess and lactate level during 4 hours of surgery between the two group A and group B with $p$ value $>0.05$.

Repeated Measures analysis of Variance (ANOVA) with Bonferroni adjustment was used for intragroup analysis of the mean difference in serum lactate level at $1^{\text {st }}$ hour, $2^{\text {nd }}$ hour, $3^{\text {rd }}$ hour and $4^{\text {th }}$ hour of operation. There were significant differences of Serum Lactate change within propofol and sevoflurane based on time $(\mathrm{F}=23.48, p<0.001)$.

There were progressive increment of serum lactate level in both groups; However there was a noticeable drop in serum lactate level in propofol group at $3^{\text {rd }}$ hour of surgery. The rate of increase of serum lactate level in sevoflurane group was the highest after 2 hours of surgery, followed by a slower rate of increase in serum lactate level after 3 hours of surgery in sevoflurane group (Figure 1). There are significant differences in the mean values of serum lactate levels at $1^{\text {st }}$, $2^{\text {nd }}, 3^{\text {rd }}$ and $4^{\text {th }}$ hour of surgery within propofol and sevoflurane group with $p$ value of $<0.05$. Nevertheless, when comparing differences in the mean values of serum lactate levels between propofol and sevoflurane group showed no significant difference of serum lactate change with $\mathrm{p}=0.186$. 
Table 5. Changes of Serum Lactate over time within Propofol and Sevoflurane group.

\begin{tabular}{lllll}
\hline \multirow{2}{*}{ Comparison } & Propofol $(\mathbf{n}=\mathbf{4 6})$ & & Sevoflurane $(\mathbf{n}=\mathbf{4 6})$ & \\
\cline { 2 - 5 } & MD $(\mathbf{9 5 \%} \mathbf{C I})$ & $*$-value & MD $(\mathbf{9 5 \%} \mathbf{C I})$ & $-0.12(-0.24,-0.01)$ \\
\hline Pre Op Lactate- 1H Lactate & $-0.14(-0.23,-0.04)$ & 0.002 & $-0.29(-0.46,-0.13)$ & $<074$ \\
Pre Op Lactate- 2H Lactate & $-0.34(-0.48,-0.20)$ & $<0.001$ & $-0.34(-0.54,-0.14)$ & $<0.001$ \\
Pre Op Lactate- 3H Lactate & $-0.29(-0.42,-0.17)$ & $<0.001$ & $0.23(-0.36,0.10)$ & $<0.001$ \\
Pre Op Lactate- 4H Lactate & $-0.15(-0.28,-0.03)$ & 0.011 & $<0.001$ & \\
\hline
\end{tabular}

$\mathrm{MD}=$ Mean Difference.

Table 6. Comparison of Serum Lactate between Group A and Group B regardless of time ( $n=92)$.

\begin{tabular}{llll}
\hline & Mean difference (95\%CI) & F-stat(df) & ${ }^{*} \boldsymbol{p}$-value \\
\hline Sevoflurane - Propofol & $0.08(-0.04,0.19)$ & $1.77(1)$ & 0.186 \\
\hline
\end{tabular}

*Repeated Measure ANOVA between group analysis was applied.

There was no significant difference of serum lactate change between propofol and sevoflurane group.

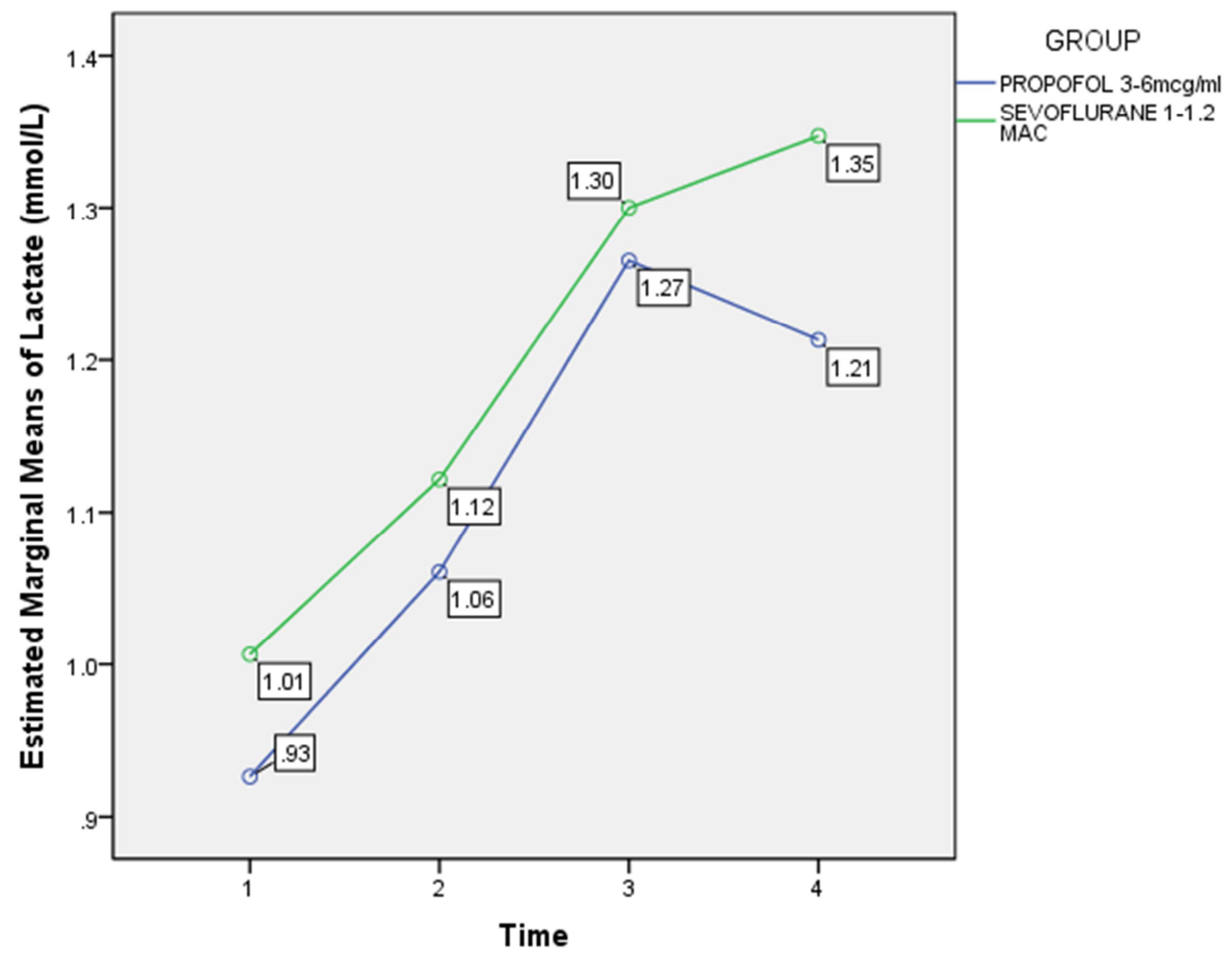

Figure 1. Profile plot of adjusted Means of Serum Lactate Level between Propofol and Sevoflurane Group.

\section{Discussion}

Propofol infusion has serious adverse effects such as metabolic acidosis, cardiac asystole, myocardial failure, rhabdomyolysis and coma at doses greater than $4 \mathrm{mg} / \mathrm{kg} / \mathrm{h}$ after 48 hours duration. In 1998, Bray proposed the term 'propofol infusion syndrome' (PRIS) to describe this clinical state associated with propofol infusions in children. PRIS was initially described as a fatal syndrome, developing after prolonged $(48 \mathrm{~h})$ high-dose $(5 \mathrm{mg} / \mathrm{kg})$ propofol infusion in critically ill patients. However, there are case reports of PRIS developing even after short-term infusion in children and adults during anaesthesia in operating rooms or sedation in intensive care units [3].

Because PRIS had been reported to occur even in patients who received infusion of propofol for short duration, we hypothesized that lactic acidosis may develop during highdose propofol infusion administered for short duration surgical procedures.

The changes during operation values of electrolytes and acid-base were tested using independent t-test. Table 4 showed there were no significant difference in $\mathrm{pH}, \mathrm{pCO}_{2}$, $\mathrm{HCO}_{3}{ }^{-}$, base excess and lactate level during 4 hours of surgery between the propofol and sevoflurane groups with $\mathrm{p}$ value of $>0.05$. 
This study revealed that there were progressive increment of serum lactate level in both propofol group and sevoflurane group; however there was a noticeable drop in serum lactate level in propofol group at $3^{\text {rd }}$ hour of surgery. The rate of increase of serum lactate level in sevoflurane group was the highest after 2 hours of surgery, followed by a slower rate of increase in serum lactate level after 3 hours of surgery in sevoflurane group.

There were some confounding factors which contribute to the result on serum lactate accumulation in the study. The degree of haemodynamic and neuroendocrinal response caused by different surgical cases and surgeons are potential confounding factors.

Decreased oxygen delivery due to hypovolaemia, hypotension, and/or anaemia during anaesthesia may contribute to hypoperfusion and hypoxaemia of peripheral tissues, causing anaerobic metabolism which could contribute to an increase in serum lactate level. In our study, the incidence of intraoperative hypotension was similar. Although there was no significant difference in SBP, intraoperative MAP, HR and core temperature between the propofol and sevoflurane groups, the duration of operation and the degree of blood loss were greatly influenced by surgeons' skills and experience in particular surgical cases.

There was no significant difference in mean age between propofol group and sevoflurane group. We observed that the propofol group (Group A) has higher mean age group when compared to sevoflurane group (Group B), with $32.17 \pm$ 12.83 for Group A versus $30.60 \pm 12.30$ years old in Group B. However, age was not known to affect blood lactate levels.

This study showed that propofol seemed to produce less serum lactate accumulation than sevoflurane. These findings have also been clinically important even if there were no complications in patients, because our patients were all fit and healthy. If this study was performed with ASA III or more scored patients, cardiac or pulmonary complications due to lipid membrane peroxidation could occur.

We observed a statistically significant increase in serum lactate levels in sevoflurane group, compared with propofol group, an alternative explanation for the difference in blood lactate levels between sevoflurane and propofol groups may be a different effect of these anaesthetics on lactate metabolism, particularly on lactate production, lactate clearance via the liver or kidneys, or the imbalance between both.

Various factors can affect lactate metabolism during surgery and anaesthesia. Release of catecholamines increases lactate production and decreases lactate clearance by decreasing hepatic blood flow. A potential explanation of an increase in serum lactate over time with sevoflurane would be an impaired liver clearance of lactate, because sevoflurane causes a dose-dependent decrease in hepatic blood flow. The liver receives $25 \%$ of cardiac output. The hepatic portal vein supplies $75 \%$ of liver blood flow and $50-60 \%$ of its oxygen. Changes to hepatic blood flow and hepatic oxygen supply, as well as intrinsic hepatic disease, all affect the capacity of the liver to metabolize lactate. Only when the liver blood flow is reduced to $25 \%$ of normal, there will be reduction in lactate clearance [5].

Lactic acidosis is considered an early sign of propofol infusion syndrome in a retrospective study investigated the changes in serum lactate and $\mathrm{pH}$ with propofol group versus isoflurane group during spine operations. Propofol patients were matched 1:2 to isoflurane patients, based on anaesthesia time and the amount of blood loss [3].

Altered lipid metabolism in the absence of cardiac ischemia or tissue necrosis may also precipitate some of the cardiac symptoms as presented in the case reports. Under normal physiology, carnitine acts as the cofactor to transport long-chain acyl groups from fatty acids into the mitochondrial matrix so they can be broken down through beta-oxidation to release energy from the citric acid cycle. Inhibition of beta-oxidation by propofol would result in the intracellular accumulation of free fatty acid and acylcarnitine complexes. High plasma concentrations of unutilized free fatty acids have been shown to possess proarrhythmogenic properties [8]. There is a case reported that lipemic blood was noted in the surgical field in a neurosurgery operation after 12.5 hours of anesthesia consisting of infusions of propofol [9]

At clinically relevant doses, propofol has been shown to inhibit the formation of ATP from its substrates and interfere with electron transfer across the mitochondria membrane causing a decrease in the transmembrane electrical potential [10].

A study published in 2007 showed that the incidence of subclinical metabolic acidosis was higher in patients receiving low-dose propofol infusion as compared to patients who did not receive propofol [11]; however, that the study was limited by the lack of an appropriate control group, and by the lack of baseline and continuous arterial blood gases sampling. Moreover, it did not examine critically ill patients or the effect of prolonged high-dose propofol infusion.

\section{Conclusion}

In conclusion, the results of our study show that short term anaesthesia with sevoflurane is associated with an increase in blood lactate levels that are more than lactate levels observed during high-dose propofol anaesthesia. However, although the difference in lactate levels within sevoflurane and propofol groups was statistically significant, the clinical importance of this finding is not clear because no patient in the sevoflurane group developed lactic acidosis in this study. This study also showed that high-dose propofol infusion at concentration of $5 \mathrm{mcg} / \mathrm{ml}$ for surgical anaesthesia for 4 hours causes neither significant hyperlactatemia nor lactic acidosis.

The influence of the anaesthetic agent on the lactate clearance and/or production might explain differences in blood lactate between the two groups in our study. However, the exact mechanisms of our findings cannot be ascertained, and prospective studies are needed to elucidate the physiology of lactate production and elimination, and the role 
of propofol in Target controlled infusion during anaesthesia of longer duration.

The results of this study also showed that the type of anaesthetic agent, either propofol or sevoflurane did not significantly influence the incidence of anaesthesiaassociated metabolic acidosis in patients undergoing short term general anaesthesia.

\section{Acknowledgement}

The authors would like to express their sincerest gratitude and thanks to Universiti Sains Malaysia and Hospital Universiti Sains Malaysia for their support. Appreciation is also extended to all the respondents who took part in this study.

\section{References}

[1] Bryson, H. M., Fulton, B. R. \& Faulds, D. (1995). Propofol. An update of its use in anaesthesia and conscious sedation. Drugs, 50(3), 513-59.

[2] Smith, I., White, P. F., Nathanson, M. \& Gouldson, R. (1994). Propofol. An update on its clinical use. Anesthesiology, 81(4), 1005-43.

[3] Rozet, I., Tontisirin, N., Vavilala, M. S., Treggiari, M. M., Lee, L. A. \& Lam, A. M. (2009). Prolonged propofol anesthesia is not associated with an increase in blood lactate. Anesth Analg, 109(4), 1105-10.
[4] Luft, F. C. (2001). Lactic acidosis update for critical care clinicians. J Am Soc Nephrol, 12 Suppl 17, S15-9.

[5] Makaryus, R., Lee, H., Yu, M., Zhang, S., Smith, S. D., Rebecchi, M., Glass, P. S. \& Benveniste, H. (2011). The metabolomic profile during isoflurane anesthesia differs from propofol anesthesia in the live rodent brain. $J$ Cereb Blood Flow Metab, 31(6), 1432-42.

[6] Barash PG, Cullen BF, Stoelting RK (1997). Clinical Anaesthesia. $3^{\text {rd }}$ edition, 15: 364-71. Lipincott-Raven, New York.

[7] Robert K. Stoelting, M., Simon C. Hillier, M. B. ChB, Frca 2006. Pharmacology \& Physiology In Anaesthetic Practice, Philadelphia, Usa, Lippincott Williams And Wilkins.

[8] Otterspoor LC, Kalkman CJ, Cremer OL. Update on the propofol infusion syndrome in ICU management of patients with head injury. Curr Opin Anaesthesiol 2008; 21: 544-51.

[9] A. Bowdle, P. Richebe, L. Lee, R. Rostomily, and P. Gabikian, "Hypertriglyceridemia, lipemia, and elevated liver enzymes associated with prolonged propofol anesthesia for craniotomy," Therapeutic Drug Monitoring, vol. 36, no. 5, pp. 556-559, 2014.

[10] Acco A, Comar JF, Bracht A. Metabolic effects in isolated perfused rat liver. Basic Clin Pharmacol Toxicol 2004; 95: 166-74.

[11] Cravens GT, Packer DL, Johnson ME. Incidence of propofol infusion syndrome during noninvasive radiofrequency ablation for atrial flutter or fibrillation. Anesthesiology. 2007; 106: 1134-1138. 